\title{
Eğitim Fakültesi Web Sitelerinin İşlevselliklerinin İncelenmesi: Sorunlar ve Öneriler*
}

Erhan DELEN**

\author{
Mustafa Serkan ABDÜSSELAM***
}

Öz

Bu çalışmanın amacı; web sitelerinde bulunması gereken özellikleri açıklayarak Türkiye'de bulunan eğitim fakültesi web sitelerinin işlevselliklerinin içerik, kullanılabilirlik, erişilebilirlik ve arama motoru uyumluluğu yönünden incelenerek eksikliklerinin tespit edilip çözüm önerilerinin sunulmasıdır. Araştırmanın verileri, 94 adet eğitim fakültesi web sitesi incelenerek elde edilmiştir. Web sitelerinin puanlamasında, 23 maddeden oluşan 'Web Sayfalarının İşlevselliğini Değerlendirme Formu' kullanılmıştır. Elde edilen verilerin anlamlandırılmasında betimsel istatistikler, t-testi ve ANOVA analizleri kullanılmıştır. Genel olarak web siteleri içerik yönünden olumlu bulunurken, en fazla erişilebilirlik yönünden eksiklikleri olduğu gözlemlenmiştir. Analiz sonuçları eğitim fakültesi web sitelerinin işlevselliklerinin kurum türüne göre farklılaşmadığını göstermektedir. Ancak 10 yaşından küçük olan eğitim fakültesi web sitelerinin daha önceki dönemde kurulan fakültelere göre içerik yönünden daha fazla eksiklikleri bulunmaktadır. Sonuç olarak, elde edilen veriler ışığında web sitelerinde bulunan eksiklikler tartışılarak çözüm önerileri sunulmuştur.

Anahtar Kelimeler: Eğitim fakültesi, web sitesi, işlevsellik, kullanılabilirlik, erişilebilirlik.

\section{Investigation of Education Faculty Websites' Functionality: Issues and Suggestions}

\begin{abstract}
The main purpose of this study was to explain the main requirements for websites and investigate the functionality of Faculty of Education websites in Turkey based on content, usability, accessibility, and search engine optimization. A total of ninety-four websites were scored with the 'Web Site Functionality Evaluation Form', which was consisted of 23 items. Descriptive statistics, t-test and ANOVA analyses were used to interpret the obtained data. In general the web sites were satisfactory based on the content. However, they had some drawbacks regarding to accessibility. The web sites' quality did not differ based on the types of the institutions. On the other hand, it was found that when the ages of institutions were considered, the websites' content of new institutions are significantly less satisfactory than the institutions that are more than 10 years old. Finally, suggestions were reported to increase the quality of websites.
\end{abstract}

Keywords: Faculty of Education, web site, functionality, usability, accessibility.

\footnotetext{
* Giresun Üniversitesi tarafından EĞT-BAP-A-250414-43 numaralı BAP bünyesinde desteklenmiştir.

** Giresun Üniversitesi Eğitim Fakültesi, Bilgisayar ve Öğretim Teknolojileri Eğitimi ABD, Giresun, erhan.delen@giresun.edu.tr

${ }^{* * *}$ Giresun Üniversitesi Eğitim Fakültesi, Bilgisayar ve Öğretim Teknolojileri Eğitimi ABD, Giresun, mustafa.serkan@giresun.edu.tr
} 


\section{GİRIŞ}

İnternet bilgiye ulaşmanın etkili bir aracı olarak hayatımızda önemli bir yere sahiptir. Gelişen teknolojinin de etkisiyle hızlı internet bağlantısına ulaşmak daha da kolaylaşmıştır. Bunun bir sonucu olarak internet kullanımı; alışverişten iletişime, eğlenceden eğitime kadar birçok alanda yaygın hale gelmiştir.

İnternet kullanımına en fazla aracilık eden ortam şüphesiz web siteleridir. Geliştirilen birçok internet tabanlı yazılım bulunsa da (örnek: akıllı telefon uygulamaları), kullanıcılar genel olarak internet kullanımını web tarayıc1ları aracılığı ile web siteleri üzerinden yapmaktadırlar (Sohn, Li, Griswold, ve Hollan, 2008) . $\mathrm{Bu}$ da web sayfalarını internet üzerinden bilgiye ulaşmanın önemli bir unsuru haline getirmiştir. İnternet teknolojisindeki gelişmeler web sitelerinin sayısında hızlı bir artışa sebep olmuştur. Bu artışı tetikleyen bir faktör de kurum ve kuruluşların resmi olarak web sitesi bulundurma zorunluluğudur. Bu artış kullanıcılara her zamankinden daha çok web sitesi seçeneği sunsa da, bu siteler kullanılabilirlik ve diğer bazı faktörler yönünden işlevsel olamayabilirler.

Bu çalışmada akademik web sitelerinin yeterlilik standartları alınyazı kapsamında tartışılarak eğitim fakültesi web siteleri açısından eksikliklerin neler olduğu saptanıp çözüm önerileri sunulmaktadır.

\subsection{Web Sitesi Tasarımı ve Yenilenmesi}

Web sitesi kalitesi çok önemlidir. Çünkü içeriği zengin ve tasarımı genel standartlara uygun bir web sitesi kullanıcıları etkileyerek ihtiyaç duyduklarında ziyaret etmelerini sağlayabilir. Bu bağlamda web sayfalarının ulaşımı kolay, içeriği yeterli ve güncel olmalıdır. Genel olarak iki yılını doldurmuş web sitelerinin birçok yönden gözden geçirilerek yenilenmesi gerekmektedir (Elges, 2002). Yenileme sürecinde web sitesinin; o zamanın internet teknolojisine ve erişim araçlarına uygun hale getirilmesi, kullanıcıların genel ihtiyaçlarını karşılaması için içerik güncellemesi yapılması ve genel temayüllere uygun bir site içi yönlendirme sisteminin kurulması amaçlanmalıdır.

Maalesef gelişigüzel hazırlanmış ve güncel olmayan birçok web sitesi, karmaşık tasarım ve yetersiz içerik yüzünden kullanıcılar tarafından etkili bir şekilde kullanılamamaktadır. Elges (2004) hazırlanan web sitelerinin gözden geçirilip aşağıda açıklanan beş faktör göz önünde bulundurularak günümüz kullanılabilirlik (usability) standartlarına uygun hale getirilmesi gerektiğini belirtmiştir.

Kullanıcılarm belirlenmesi: İnternet sitesi kullanıcıları, müşteriye benzetilebilir. Yani, sunulan içeriğin bu siteyi ziyaret eden kişinin ihtiyaçlarına cevap vermesi gerekir. Akademik web sitesi mevcut öğrencilerden aday öğrencilere, akademik personelden idari personele kadar birçok kullanıcıya hizmet vermektedir (Gullikson vd., 1999). Bir akademik web sitesi hazırlanırken potansiyel kullanıcılar göz önüne alınarak, içerik ve kullanılabilirlik standartları bu kullanıcılara göre belirlenmelidir. İnternet ekonomisinde kullanılabilirlik öncesine göre daha fazla ön plana çıkmıştır (Nielsen, 2000). Bu yüzden bir web sitesi, önünde sayısız seçenek olan bir kullanıcıyı memnun ederek kendine bağlayabilmelidir. Bu da kullanıcının, ihtiyacı olan bilgiye kolay ve hızlı bir şekilde erişimi ile mümkün olabilir. Akademik web siteleri potansiyel kullanıcıların ihtiyaçlarına cevap verebilecek şekilde oluşturulmalıdır.

Web sayfasının amactnın belirlenmesi: Hazırlanan bir web sayfasinın uygun bir ana amacının belirlenmesi gerekir. Böylece bu amaca uygun içeriğin, tasarımın ve site içi dolaşım yapısının (yönlendirme) belirlenmesi daha kolay olacaktır. Örneğin, üniversitede yürütülen projeler hakkında bilgilerin kullanıcılara sunulması, bir 
akademik web sayfasının amacı olarak kabul edilebilir.

Isslevlerin belirlenmesi: Bir web sitesinin ana amacı belirlendikten sonra, bu siteyi oluşturan sayfaların içeriğinin ayrı ayrı işlev tanımı yapılmalıdır. Unutulmamalıdır ki bir akademik web sitesinin karşılaması gereken birçok işlev olabilir. Bu yüzden bilgisayarla tasarım aşamasına geçilmeden önce bu işlevler yazılarak öncelikleri belirlenebilir ve sonrasında çıkabilecek zorluklar öngörülerek ekstra zaman, para ve düzeltmelerden kaçınılabilir (Elges, 2004). Örneğin kâğıt üzerinde web sayfasının akış diyagramı çizilerek bu işlevlerin kullanılabilirliği test edilebilir.

Ortam zorluklarının belirlenmesi: Web sitesi çok geniş kullanıcı grupları tarafından ziyaret edilebilir. Bu yüzden ziyaretçilere sunulan web sayfası içerikleri kullanıcıların farklı ihtiyaçları göz önünde bulundurularak sunulmalıdır. Örneğin, göz bozukluğu olan yaşlı bir kullanıcı veya fiziksel engelli bir kullanıcı da sunulan içerikten en uygun bir şekilde yararlanabilmelidir. Brophy ve Craven (2007)'e göre, değişik erişim teknolojileri ve uygun bir arayüz tasar1mı ile sunulan web sayfası içerikleri, bilgiye erişimi artırabilir. Kullanıcıya sayfadaki yazının boyutunu değiştirebilme seçeneğinin sunulması buna bir örnek olarak verilebilir.

Teknolojinin belirlenmesi: Bir web sayfasına erişimi etkileyen faktörler internet bağlantı hızı, ekran çözünürlüğü ve kullanılan aygıt özelliği (örnek: dizüstü, akıllı telefon) olarak sıralanabilir. Birçok kullanıcının hızlı internet bağlantısına sahip yeni bilgisayarları olsa bile, halen kısıtlı şartlarda internete erişen kullanıcılar da olabilir.

Nielsen (2000)'e göre, bir web sitesi iki sene önceki sürüme sahip olan bir web tarayıcısı ve eklentileri ile çalışabilmelidir. Bu şekilde kullanıcıların ilgili web sitesine olan erişimleri en- gellenmemiş olur. Unutulmaması gereken bir nokta da günümüzde web sitelerine bilgisayarların yanı sıra akıllı telefonlar, tabletler ve benzeri aygitlar tarafından da erişim yapılabilmesidir. Bu yüzden, bir akademik web sitesi hazırlanırken yaygın kullanılan tüm aygıtlar göz önünde bulundurulmalıdır.

Sıralan bu beş faktörün yanı sıra alınyazında web sitelerinin amaca uygun ve kullanılabilir olması, yani işlevselliğinin sağlanması için dikkat edilmesi gereken başka faktörler de bulunmaktadır. Bu faktörler; İçerik (Khazaal, Chatton, Zullino, ve Khan, 2012), Kullanulabilirlik (Chiew ve Salim, 2003), Erişilebilirlik (Hackett, Parmanto, ve Zeng, 2004) ve Arama Motoru Uyumluluğudur (Zhang ve Dimitroff, 2005). Bu faktörler web sitelerini geliştirirken ve mevcut siteleri değerlendirirken dikkate alınırsa akademik web sitelerinin daha işlevsel bir hale gelmeleri sağlanabilir.

\subsection{Web Sitesi İşlevsellik Kriterleri}

\subsection{1 İçerik (Content)}

İçerik bir web sitesi için en önemli unsurlardan birisidir. Çünkü kullanıcılar web sitelerini öncelikli olarak tasarımları için değil, içerikleri için ziyaret ederler (Nielsen, 1999; Richards ve Hanson, 2004). Web sitesinde çok ve gereksiz bilgi olmaması gerekir. Özellikle site içeriği kullanıcıların ihtiyaçlarını karşılayabilecek, iyi organize edilmiş, faydalı bilgilerden oluşmalıdır. Bu bağlamda, bir akademik web sitesinin içeriği, kullanıcıların ihtiyaçları ve benzer işlevsel sitelerin içerikleri temel alınarak oluşturulmalıdır. Uygun hazırlanmış web sayfası içeriği, sitenin arama motorlarında kolay ulaşılabilmesine de katkıda bulunur (Zhang ve Dimitroff, 2005).

Bir akademik web sitesi sadece düz yazı ile sunulmuş bilgilerden oluşmamalıdır. Çünkü internet kullanıcıları sabırsızdırlar ve ihtiyaç duydukları içeriğe hızlı ve eğlenceli bir şekilde 
erişmek isterler. Bu bağlamda internet ortamındaki yazıların sunuş formatı sıkıcı olamayacak bir şekilde hazırlanmalıdır (Nielsen, 1999). Bu yüzden, içerik ile uygun bazı resim, animasyon, grafik, tablo, video vb. görsel araçların kullanılması kullanıcıların istedikleri bilgiye kolay ulaşabilmelerine katkıda bulunabilir. Ancak sitenin genel içeriği, sayfa yüklenme hızını olumsuz etkilemeyecek şekilde organize edilmelidir. Örneğin yüksek çözünürlüklü birçok resmin gösterildiği bir web sayfası yavaş açılacağından kullanıcıları memnun etmeyecektir.

İçerik ile ilgili dikkat edilmesi gereken en önemli unsurlardan birisi de içeriğin güncel olmasıdır. Web sitesi düzenli olarak güncellenmelidir çünkü kullanıcılar bu sayfaları güncel ve güvenilir bilgiye ulaşmak için ziyaret ederler. İçeriği daha kolay bir şekilde güncel tutmak ve değiştirebilmek için bazı teknik altyapılar siteye entegre edilebilir. Böylece site yöneticileri içeriği dinamik olarak güncelleyebilirler. Ayrıca, kullanıcılara sunulan duyuru, bilgi ve belgelerin de ekleme, güncelleme ve yenileme tarihleri kullanıcılara sunulmalıdır. Bunun yanı sıra, zamanı geçmiş bilgi ve belgelerin web sayfalarından kaldırılması gerekmektedir. Örneğin bir önceki akademik yıla ait sınav programının ziyaretçilere bir katkısı olmayacaktır. Aksine istedikleri bilgiye ulaşmada zorluğa sebep olacaktır. Site içeriklerinin anlaşılır ve uygun bir şekilde organize edilerek hazırlanması içerikleri kontrol etme ve düzenleme işlemlerinde de kolaylık sağlayacaktır.

\subsubsection{Kullanılabilirlik (Usability)}

Farklı ziyaretçi gruplarının farklı ihtiyaçları ve özellikleri olabilir. Web sitesinin söz konusu bu ziyaretçilerin beklentilerini karşılayabilmesi gerekir. Uygun bir şekilde hazırlanmış bir akademik web sitesi, kolay kullanılabilir bir arayüze sahip olmalıdır. Ayrıca site içi yönlendirme mantığı ile kullanıcıların arzu ettikleri bilgilere kolayca ulaşabilmeleri de sağlanmalıdır. Bu yüzden kullanıcıların farklılıkları gözetilerek aynı içeriğe değişik ulaşım yolları sunulmalıdır (Gullikson vd, 1999).

Kullanıcılar bir web sitesini ziyaret ettikleri zaman amaçlarına uygun olarak istedikleri içeriğe nasıl ulaşacaklarını kolayca anlayabilmelidirler. Bu da ancak etkili bir tasarım ve site içi yönlendirme sistemi ile mümkün olacaktır. Kullanıcıları istedikleri sayfalara yönlendirmek zor bir iştir. Ziyaretçilerin siteye eriştiklerinde ilk karşılaştı̆̆ı yer olmasından dolayı, web sitesindeki ana sayfa çok önemlidir. Bu sayfa bir web sitesinin ziyaret edilmesini büyük oranda etkilemektedir. Bundan dolayı bu sayfalar kullanıcının ilgisini çekecek bir şekilde hazırlanmalıdır (Nielsen, 2000). İlk görünüşte sade ve kolay anlaşılan bir arayüze sahip ana sayfa, kullanıcıların ilgisini çekecek ve site içi yönlendirmeyi kolaylaştıracaktır. Ayrıca kullanıcıların bulundukları bir sayfadan ana sayfaya ulaşarak, istedikleri sayfalara kolayca geçiş yapabilmeleri önemlidir.

Bazı bilgilere sadece bir yolla değil, birden fazla sayfadan veya menüden ulaşılması; kullanıcıların istedikleri bilgiye erişimini hızlandıracaktır. Bir akademik personelin iletişim bilgilerine fakülte ana sayfasından ve personelin kendi bölüm sayfasından ulaşılabilmesi buna bir örnek olarak verilebilir. Kullanılabilirliğin bir başka göstergesi de yapılacak işlemin kısa sürede yapılabilmesidir. Bu yüzden site içi arama özelliği, iyi organize edilmiş bir site haritası ve alfabetik içerik seçenekleri bilgiye ulaşımı hızlandıracaktır. Örneğin öğrenci organizasyonlarının listelendiği uzun bir sayfada alfabetik içerik ile istenilen organizasyona kolayca ulaşılabilir.

İnternet popüler olmaya başladığı yıllarda kullanıcılar çok gösterişli ve ilginç tasarımları 
tercih ediyorlardı. Fakat günümüzde web sitelerinin daha sade, kullanımı kolay ve tutarlı ve sık değişmeyen bir arayüz görünümüne sahip olmaları tercih edilmektedir (Morkes ve Nielsen, 1997). Google ana sayfası bunun için güzel bir örnektir. Çok karmaşık ve ihtişamlı bir dizayn, web sitelerinin kullanımını zorlaştırabileceği gibi, düşük seviyedeki teknolojik aygıtlarla bu sayfalara erişimi de engelleyecektir. Web sitesi yapım aşamasında gerekirse kullanıcı arabirimi (UI) uzmanlarından faydalanılmalıdır (Nielsen, 1999).

Hazırlanan web sitelerinin kullanılabilirlikleri farklı metotlar kullanılarak ölçülebilir ve varsa aksaklıklar giderilebilir. Genel anlamda Atterer, Wnuk, ve Schmidt (2006) çalışmalarında uygulanabilecek kullanılabilirlik testlerinden söz etmişlerdir. Akademik web sitelerinin incelenmesi hakkında da yapılan çalışmalar vardır (Astani ve Elhindi, 2008; Gullikson vd., 1999; Liu., Liu, Hwang, 2011; Stover ve Zink, 1996; Thompson, Burgstahler, ve Comden, 2003).

Web sitelerinin işlevselliği hakkında birçok araştırma yapılmıştır. Brophy ve Craven (2007) kullanılabilirlik ile ilgili çalışmalarında içerik organizasyonunun ve site içi dolaşım sisteminin en önemli iki faktör olduğunu belirtmiştir. Aynı çalışmada uygun olmayan site içi dolaşım sistemi kullanan kişiler, haritasız bir şekilde bir şehirde kaybolan kişilere benzetilmiştir. Diğer bir ifade ile bir web sitesinin amacına uygun içeriği ve cazip bir tasarımı olabilir, ancak kullanım zorluğu sebebiyle işlevsiz hale gelebilir (Gullikson vd, 1999). Bir web sayfasının kullanılabilirliği; ilgili sayfanın kullanıcı tarafından kolayca, akıcı ve seri bir şekilde kullanımı şeklinde ifade edilmektedir (Hiller, 2003). Kullan1labilirlik, internet üzerinden hizmet veren kurumlar için çok önemlidir ve kullanıcı memnuniyeti üzerindeki etkisi büyüktür (Flavian, Guinaliu ve Gurrea, 2006). Yani kullanıcının bir web sitesini ziyaret etme sıklığı, site kullanı- mından ne kadar memnun kaldığına bağlıdır (Gullikson vd, 1999 ). Yapılan bir çalışmada, kullanıcıların ancak \%26'sının ana sayfada iken istenilen işlemi yapabildikleri bulunmuştur (Nielsen, 2000). Bu sonuç bizlere kullanıcıların aradıklarını kolayca bulamadıklarını göstermektedir. Bu, web sitesi için olumsuz bir durumdur. Bu olumsuzluğun etkileri uygun tasarımlarla azaltılabilir (Norman, 1988).

Web sitesinin çok basit ve sade site içi dolaşım sistemi olmalıdır. Özellikle kullanıcı hangi menüden nereye ulaşabileceğini kolayca anlayabilmelidir. Bir web sayfası çok yararlı bilgiler içerebilir, ancak ziyaretçiler tarafından erişilemedikleri zaman bir işe yaramazlar. Bu yüzden akademik web siteleri bazı ilave destekleyici özelliklerle geniş ziyaretçi kitlesinin ilgili siteden daha çok verim almasını sağlayabilirler. Çoklu menü, site içi arama motoru, site haritası, alfabetik içerik ve sıkça sorulan sorular gibi bazı araçlar site içerisinde kullanım kolaylığı sağlar (Gullikson vd., 1999).

\subsubsection{Erişilebilirlik (Accessibility)}

Bir akademik web sitesi çok iyi hazırlanmış bir içeriğe sahip ve kullanılabilirliği mükemmel olabilir. Ancak kullanıcılar söz konusu siteye sorunsuz bir şekilde erişemiyorsa, site işlevini tam olarak yerine getiremeyecektir. Kullanıc1ların web sitesinin tüm içeriğine erişebilmek istedikleri bir gerçektir (Richards ve Hanson, 2004). Bir web sitesi için erişilebilirlik, her kullanıcının herhangi bir engel veya ortam zorluğuna takılmadan içeriğe ulaşabilmesi olarak tanımlanmaktadır (Mankoff, Fait, ve Tran, 2005). Bu yüzden, site tasarlanırken siteye erişim için kullanılacak cihaz, internet bağlantı hızı ve diğer ilgili gereksinimler göz önünde bulundurulmalıdır. Böylece ilgili site çeşitli durumlarda bulunan kullanicilara daha sorunsuz hizmet verebilecektir. 
Web sitelerinde erişilebilirlik iki yönden incelenebilir. Bunların birincisi internet sitesine erişimine aracilık eden aygıtların, yazılımsal ve donanımsal nitelikleridir. Örneğin, cihazların ekran çözünürlüğü istenilen web sitesinin görüntülenmesini doğrudan etkileyen bir faktördür. Bu yüzden kullanıcıların çoğunluğunun siteye ulaşabilmesi için web sayfaları uygun çözünürlüklerde tasarlanmalıdır. Tasarlanan sitenin hangi çözünürlükte nasıl görüntülendiği tespit edilmeli ve gerekli düzenlemeler yapılmalıdır. Bunun için internet ortamında çalışan bazı uygulamalar da mevcuttur (Kyleschaeffer, 2015). Bu uygulamalara bir örnek olarak http:/quirktools.com/screenfly/ adresi verilebilir.

Bununla ilişkili olarak hazırlanan sayfaların yaygın tüm web tarayıcılarında doğru bir şekilde gösterildiğinden ve tüm fonksiyonların çalıştığından emin olunmalıdır. Eğer hazırlanan site bazı web tarayıcıları tarafından desteklenmiyorsa, kullanıcilara en uygun tarayıcı tavsiye edilerek bilgi verilmelidir.

İnternet hızı da web sayfalarına erişimi etkileyen bir faktördür. Hazırlanan akademik web sitesi ilgili kullanıcıların sahip olduğu internet hızında çalışabilecek şekilde hazırlanmalıdır. Örneğin yüklenmesi zor olan yüksek çözünürlüklü bir video, kullanıcıların sayfaya erişimini zorlaştıracağından tercih edilmemelidir.

Mobil aygıtlar da günümüzde web sayfalarını ziyaret etmek için yaygın bir şekilde kullanılmaktadırlar. Akademik web sayfa tasarımcıları bu durumu dikkate almalıdırlar. Tasarımcılar ilgili web sitesini mobil cihazlarda da sorunsuz kullanılabilir şekilde hazırlayabilecekleri gibi aynı sitenin mobil sürümünü de hizmete sunabilirler. Böylece mobil aygıt kullanıcılarının siteden yararlanmaları sağlanacaktır.

Web sitelerinin erişilebilirlikleri ikinci olarak kullanıcıların özel durumları ile ilişkilidir.
Yukarıda da ifade edildiği gibi akademik web sitesi kullanıcıları arasında çok farklı özellik ve ihtiyaçlara sahip kişiler olabilir. Bu kullanıcılardan bazıları engelli ve yaşlı kullanıcılardır. Bir web sitesi ancak engelli kullanıcıların da kullanabileceği standartta hazırlanmışsa tamamen erişilebilirdir (Lazar, 2003). Bu kişiler özellikle görsel sunumlarda (yazı boyutu, yazı rengi, arka plan, vb.) zorluk yaşayabilmektedirler (Richards ve Hanson, 2004). Bu gibi kişilerin web sayfalarından en iyi şekilde yararlanabilmeleri için siteler tasarlanırken gerekli tedbirler alınmalıdır. Bu tedbirlerden bir tanesi görme zorluğu olan kullanıcılar için metin boyutu ayarlayabilme özelliğidir. Bu sayede gerektiğinde kullanıcılar site içindeki metinlerin boyutunu değiştirebilirler. Buna ilave olarak sitede kullanılan resimlerin uygun bir şekilde isimlendirilmesi ve alternatif etiketlenme kullanımı, görme zorluğu olan kullanıcıların bazı yazılımlar sayesinde göremedikleri görsel içeriklerin ne ile ilgili olduklarını dinleyerek öğrenebilmelerini sağlar.

Günümüz internet teknolojisi kullanıcilara öncekinden daha fazla etkileşimli kullanım özellikleri sunarak web kullanımlarını kolaylaştırmaktadır. Örneğin kullanılan birçok web tarayıcısı; web sitelerinde bulunmasa bile, yazı boyutu değiştirebilme gibi bazı özellikleri kullanıcılarına sunmaktadır. Ancak çoğu kullanıcının bunların kullanımından ve varlığından haberleri yoktur (Richards ve Hanson, 2004).

Çoğu web sitesi erişilebilirlik ve evrensel tasarım ile ilgili ilkeleri görmezden gelmektedir (Sullivan ve Matson, 2000). Aslında web geliştiricileri, basit tasarım ve kodlama değişiklikleri ile tavsiye edilen talimatları dikkate alarak site erişebilirliğini kolayca arttırabilirler (Spindler, 2002; Lazar vd, 2003; Lazar, Dudley-Sponaugle ve Greenidge, 2004). 


\subsubsection{Arama Motoru Uyumluluğu}

Web sitesi kullanıcıları iki grup altında incelenebilir. Bunlar site yayıncıları ve siteye erişip yararlanan kişilerdir (Zhang ve Dimitroff, 2005). Arama motorları, ikinci gruptaki kullanıcıların en hızlı şekilde doğru web sitesine erişilebilmelerini sağlayan aracı bir yapıdır. Bir web sayfasının geniş bir kullanıcı kitlesine ulaşabilmesi için uygun arama motoru uyumluluğu yapılmış olması gerekir. Bu işlemin genel amacl, web sitesinin arama motorlarında ilk siralarda listelenmesini sağlayarak site erişilebilirliğini ve ziyaretini arttırmaktır (Zhang ve Dimitroff, 2005). Bir web sitesinin arama motorlarında indekslenerek uygun bir şekilde gösterilmesi birçok faktöre bağlıdır. Arama motorları, web sitesi indeksleme yöntemlerini sürekli değiştirmektedirler (Lawrence ve Giles, 1999). Web sitesi tasarımcılarının bu yöntemleri olabildiğince göz önünde bulundurarak, gerekli uyumlulukları yapmaları gerekmektedir. Bunun yanı sıra, bir web sitesinin popülaritesi, site tasarımı dışında farklı bazı etkenlere de bağlıdır. Örneğin, diğer bazı sayfaların ilgili web sitesine verdikleri linkler, o sayfanın ara- ma motorundaki gösterimini olumlu yönde etkilemektedir (Zhang ve Dimitroff, 2005). Akademik web sitelerinin arama motoru uyumluluğu yönünden uygun kullanıcılara kolayca ulaşmasını sağlamak adına dikkat edilmesi gereken bazı noktalar aşağıda sıralanmıştır.

\section{- Uygun Başlık ve Meta Tag Kullanımı:}

Web sitesinde bulunan her bir sayfa için ilgili sayfanın içeriğine uygun özgün bir başlık, anahtar sözcükler ve açılama yazmak; o sayfanın arama motorlarında üst sıralarda görünmesini sağlayacaktır. Bu bilgiler, ilgili sayfa arama motoru tarafından listelendiğinde özet bir şekilde sayfa linkinin altında yer almaktadır. Bu da kullanıcıların aradıkları sayfaya hatasız ulaşmalarına yardımcı olur. Tablo 1'de başlık ve meta tag kullanımına ilişkin uygun ve uygun olmayan iki örnek gösterilmiştir. Uygun örnekte kurum adı altında ilgili kuruma ait özet bir bilgi verilirken, uygun olmayan örnekte meta tag kullanımına uygun olmayan bir içerik görülmektedir.

Tablo 1. Web Sayfasında Başlık ve Meta Tag Kullanımı

\begin{tabular}{|c|c|}
\hline Web sayfası içinde uygun bir açılama kullanılmış. & $\begin{array}{l}\text { Web sayfası içinde uygun olmayan bir açıklama } \\
\text { kullanılmış. }\end{array}$ \\
\hline$\frac{\text { Hukuk Fakültesi - Marmara Üniversitesi }}{\text { hukuk.marmara edu trrl - Translate this page }}$ & Hacettepe Öniversitesi Tıp Fakültesi \\
\hline 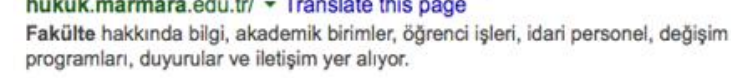 & 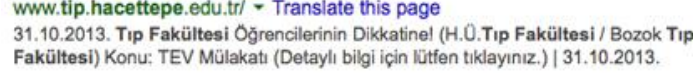 \\
\hline $\begin{array}{l}\text { - Arama Motorlarına Uyumlu Sayfa Uzan- } \\
\text { tısı Kullanımı }\end{array}$ & $\begin{array}{l}\text { şeklinde sayfa uzantısı kullanılmıştır. Ancak } \\
\text { uygun olmayan örnekte “../index.php }\end{array}$ \\
\hline $\begin{array}{l}\text { Web sitesi içindeki sayfaların link uzantıları da } \\
\text { ilgili sayfaya uygun ve arama motoru tarafın- } \\
\text { dan anlaşılacak şekilde seçilmelidir. Tablo 2'de }\end{array}$ & $\begin{array}{l}\text { ?id=333" gibi karmaşık bir ifade tercih edilmiş- } \\
\text { tir. Bu durumda arama motorları, ilk web say- } \\
\text { fasını daha doğru bir şekilde indeksleyecektir. }\end{array}$ \\
\hline
\end{tabular}
gösterilen uygun örnekte ".../egitim-fakultesi"

Tablo 2. Web Sayfası Uzantısı Kullanımı

\begin{tabular}{|c|c|}
\hline Uygun örnek & Uygun olmayan örnek \\
\hline Mersin Üniversitesi | Eăitim Fakültesi | & Bilgisayar ve Ŏğretim Teknoloiileri Eăitimi: Giresun Üniversitesi \\
\hline www.mersin.edu.tr/akademikf/egitim-fakultesi - Translate this page & egitim. giresun.edu.tr/index.php?id $=333$ - Translate this page \\
\hline $\begin{array}{l}\text { - Arama Motorlarına Uyumlu Link Kulla- } \\
\text { nımı }\end{array}$ & $\begin{array}{l}\text { Site içindeki sayfalara bir resim üzerinden değil } \\
\text { de, vazı seklinde olan ve ilgili sayfayı kısaca }\end{array}$ \\
\hline
\end{tabular}


tanımlayan bir yazı linki üzerinden erişilebilirliği sağlanmalıdır. Eğer resim üzerinden bir link oluşturulacaksa, o resmin alternatif isimlendirilmesi ilgili sayfaya uygun bir şekilde yapılmalıdir. Bu sayede arama motorları, bu linkleri de göz önüne alarak indeksleme yapacak ve sitenin görüntülenmesine katkı sağlayacaklardır. Aynı zamanda görme zorluğu çeken ve yazıyı seslendirerek web sitesini kullanan kullanıcılara da kolaylık sağlanmış olacaktır.

- Robots.txt Dosyası Kullanımı
Arama motorları karmaşık bir çok algoritmanın yanı sıra web sitelerinde bulunan Robots.txt adlı bir dosyayı tarayarak web sitesinin içeriğini indekslerler. Bu dosya arama motorlarına neyi indeksleyip neyi indekslemeyeceklerini belirtir. Yani site yöneticisi isterse bazı içeriklerin indekslenmesini sınırlayabilir. Eğer sınırlama istenmiyorsa uygun içerikli basit bir Robots.txt dosyası hazırlanarak site kök dizinine kaydedilebilir. Resim 1'de örnek bir dosya içeriği gösterilmiştir.

User-agent: *

Allow: /

Resim 1. Robots.txt Dosyası İçeriği 1

Resim 1'deki Robots.txt dosyası içeriğine göre ilgili sitedeki tüm içeriğin arama motorları tarafından indekslenmesine izin verilmiştir.
Resim 2'deki örnekte ise bazı içeriklerin indekslenmesi engellenmiştir.

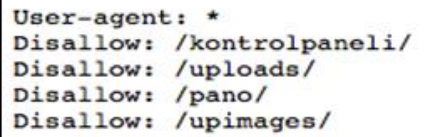

Resim 2. Robots.txt Dosyası İçeriği 2

- Sitenin Popülaritesini Artırmak:

Bir web sitesinin kullanıcılar tarafından çok ziyaret edilmesi isteniyorsa, farklı yöntemler kullanarak ilgili sitenin popülaritesi arttırılmalıdır. Bu da daha çok diğer bazı sitelerin ilgili sitelere bağlantı vermesi ile yapılabilir. Örneğin uzaktan eğitim merkezine ait bir akademik web sitesine il Milli Eğitim Müdürlüğü sitesinden erişilebilmesi, ilgili akademik web sayfasının daha fazla kullanıcı tarafından ziyaret edilmesine ve arama motorlarında üst sıralarda gösterilmesine yardımc olacaktır. Sosyal medya kullanımı da akademik web sitelerinin popülaritesini arttırmak için kullanılabilir. Özellikle Facebook ve Twitter gibi çoğu kişinin takip ettiği platformlarda yapılacak uygun tanitımlar sitelerin kullanımını arttıracaktır (Dal ve Dal, 2015; Çoban ve Tüfekçi, 2015).

\section{- Web Sitesinin Trafiğini Denetlemek:}

Kullanılan bir web sitesinin trafiğini denetlemek çok önemli ve yararlıdır. Site yöneticileri uygun araçları kullanarak ziyaretçi profilleri ve siteyi görüntüleyen aygıtların özellikleri hakkında ayrıntılı bilgiye sahip olabilirler. Böylece sitenin yenilenmesi aşamasında site kullanıcılarına göre düzenlemeler yapmak mümkün olur. Örneğin Google Analytics isimli araç kullanıcıların konumu, kullandıkları aygıtın türü, sayfaya ulaşma yolları gibi birçok bilgiyi site yöneticilerine sunmaktadır. 
Yukarıda belirtildiği gibi, web sitelerinin işlevsel bir yapıda olabilmeleri için birçok faktör göz önünde bulundurulmalıdır. Türkiye'deki eğitim fakültelerinin web siteleri bu faktörler açısından incelendiğinde bu sitelerin geliştirilmesinin yararlı olacağı belirtilmektedir (Çoban, Tüfekçi, 2015). Bu eksikler web sitelerinin amaçlarına ulaşma açısından sorunlara neden olabilir. Örneğin, eğitim fakültesine yeni kayıt yaptırmış bir öğrenci, yaptığı çalışmayla ilgili ortak konu alanında uzman arayan lisansüstü bir öğrenci ya da bir akademisyen veya karş1laştığı sorunla ilgili kime başvuracağ 1 hakkında bilgi almak isteyen kayıtlı bir öğrenci aradı̆̆ güncel bilgiye erişimde problem yaşıyorsa kullanılan web sitesinin işlevsel olduğu söylenemez. Bu nedenle genelde tüm kurumsal web sitelerinin özelde ise eğitim fakültesi web sitelerinin işlevsel olması dikkate alınması gereken önemli bir konudur. Bu konu dikkate alınarak Türkiye'deki Eğitim Fakültesi web sitelerinin işlevselliklerinin incelenmesi, bu konudaki sorunlara dikkat çekilmesi ve önerilerin paylaşılması bu araştırmanın amacını oluşturmaktadır. Bu amaç bağlamında aşağıdaki araştırma sorularına yanıt aranmaktadır.

1- Türkiye'deki Eğitim Fakültesi Web Siteleri; içerik, kullanılabilirlik, erişilebilirlik ve arama motoru uyumluluğu faktörleri açısından ne kadar işlevseldir?

2- Web sayfası işlevselliği fakültelerin türüne, kuruluş yılına göre anlamlı farklılık göstermekte midir?

3- İşlevsellik açısından karşılaşılan en önemli sorunlar nelerdir?

\section{YÖNTEM}

Bu çalışma 2015 yılında yapılan bir betimsel tarama araştırmasıdır. Çalışma kapsamında Türkiye'de hizmet vermekte olan tüm eğitim fakültelerinin web siteleri, alınyazında üzerin- de durulan faktörler dikkate alınarak geliştirilen “Web Sitelerinin İşlevselliğini Değerlendirme Formu" kullanılarak incelenmiştir. Verilerin toplanması için kullanılan form, ilk olarak iki araştırmacı tarafından konuya ilişkin önceden yapılan çalışmalar kapsamlı bir şekilde taranarak oluşturulmuştur. Daha sonra internet teknolojisi alanında uzman dört araştırmacıdan uzman görüşü alınarak değerlendirme formu son haline getirilmiştir.

Sonuç olarak değerlendirme formu dört ana başlık altında (İçerik (9 madde), Kullanılabilirlik (4 madde), Erişilebilirlik (4 madde), Arama Motoru Uyumluluğu (6 madde)) 23 adet niteliği değerlendiren maddeden oluşmaktadır. Dört ana bölüm sirasiyla en fazla 43, 15, 19, 23 puan alınacak şekilde oluşturulmuş ve her incelenen web sitesi toplamda 100 puan üzerinden değerlendirilmiştir. $\mathrm{Bu}$ maddelerin yanı sıra incelenen fakültelerin kuruluş senesi, kurum türü gibi bazı bilgiler de toplanmıştır. Çalışmanın yapıldığ1 tarihte, Yükseköğretim Kurumunun verilerinden yararlanılarak Türkiye'de 97 adet Eğitim Fakültesi bulunduğu tespit edilmiştir. $\mathrm{Bu}$ fakültelerin tamamı çalışmanın kapsamına alınmıştır. Ancak verilerin toplandığı tarihte üç fakültenin web sitesinin olmamasından dolayı veri analizinde 94 tane fakülte ele alınmıştır.

\subsection{Veri Toplama ve Analiz Süreci}

İlk olarak, Türkiye'de bulunan eğitim fakültelerinin güncel listesi Yükseköğretim Kurumu web sitesinden temin edilmiştir. Daha sonra hazırlanan değerlendirme formu çevrimiçi bir ortama aktarılarak veri toplamak için hazır hale getirilmiştir. Veriler, belirtilen web sitelerini birbirinden bağımsız olarak iki araştırmacının çevrimiçi değerlendirme formunu kullanarak puanlaması ile toplanmıştır. Puanlama aşamasında her web sitesi ayrıntılı bir şekilde incelenmiş ve ilgili maddelere göre puanlandırma yapılmıştır. Her bir web sitesinin incelenmesi yaklaşık 10 dakika almıştır. Veri toplama işlemi 
bittikten sonra iki araştırmacı tarafından ayrı ayrı toplanan puanların ortalaması alınarak her fakülte web sitesinin içerik, kullanılabilirlik, erişilebilirlik ve arama motoru uyumluluğu puanı tespit edilmiştir. Verilerin analizleri IBM SPSS $20 \AA$ programında yapılmış olup betimsel istatistiklerden yüzde, ortalama ve standart sapma kullanılmıştır. Kurum türü ve kuruluş yılına göre farklılaşmalar ise t-testi ve ANOVA analizleri ile incelenmiştir.

\section{BULGULAR}

Bu kısımda ilk önce çalışmada incelenen eğitim fakültelerine ilişkin olarak betimleyici bilgiler gösterilmiştir (Tablo 3). Çalışmaya dâhil edilen kurumlardan 79 adedi devlet kurumu, 15 adedi vakıf kuruluşudur. Kurumların yaşları incelendiğinde 1 ile 40 arasında değiştiği anlaşılmıştır. Bu yüzden kurumlar dört farklı yaş grubunda incelenmiştir.

Tablo 3 - Türkiye'de Eğitim Fakülteleri*

\begin{tabular}{crr}
\hline Üniversite Türü & Adet & $\%$ \\
\hline Devlet & 79 & 84 \\
Vakıf & 15 & 16 \\
Toplam & 94 & 100 \\
\hline Kurum Yaşı & & \\
\hline $1-10$ & 29 & 31 \\
$11-20$ & 35 & 37 \\
$21-30$ & 13 & 14 \\
$31-40$ & 17 & 18 \\
Toplam & 94 & 100 \\
\hline${ }^{*} 2015$ yll & &
\end{tabular}

Eğitim fakültesi web sitelerinin işlevsellikleri geliştirilen değerlendirme formu kullanılarak puanlanmıştır. Tablo $4^{\prime}$ te kurumların dört ana başlık altında aldıkları puanlara ilişkin veriler gösterilmektedir.
İncelenen ana başlıklara ilişkin alınabilecek en fazla puan parantez içinde gösterilmiştir. Alınan puanların minimum, maksimum, ortalama ve standart sapma değerleri ile alınabilecek en fazla puana göre yüzdeliği gösterilmiştir.

Tablo 4. Web Sitesi İşlevselliği Değerlendirme Sonuçları

\begin{tabular}{|c|c|c|c|c|c|}
\hline Değerlendirme Türü & Min & $\operatorname{Max}$ & $X$ & SS & $\%$ \\
\hline İçerik (43) & 21,5 & 41 & 32,6 & 4,30 & 76 \\
\hline Kullanılabilirlik (15) & 6 & 15 & 9,9 & 2,17 & 66 \\
\hline Erişilebilirlik (19) & 5 & 15,5 & 7,7 & 1,90 & 41 \\
\hline Arama Motoru Uyumluluğu (23) & 5 & 19,5 & 11,4 & 3,10 & 50 \\
\hline Toplam (100) & 45 & 82 & 61,6 & 7,68 & 61,6 \\
\hline $\begin{array}{l}\text { Tablo } 4 \text { 'ten de anlaşılacağı üzere incelenen } 94 \\
\text { adet web sitesinin aldığı toplam puanların } \\
\text { ortalaması } 61,6 \text { puandır. Bir diğer ifade ile bir } \\
\text { eğitim fakültesi web sayfasında bulunması } \\
\text { gereken özellikler yönünden web sayfaları } \\
\text { genel olarak \% } 66,1 \text { oranında olumlu bulunmuş- } \\
\text { tur. Ana başlıklar ele alındığında ise en düşük } \\
\text { yeterliliğin \%41 ile erişilebilirlik özelliğinin, en }\end{array}$ & \multicolumn{5}{|c|}{$\begin{array}{l}\text { yüksek yeterliliğin de } \% 76 \text { ile içerik özelliğinin } \\
\text { sahip olduğu görülmektedir. Bu sonuçtan } \\
\text { fakülte web sitelerinin en fazla içeriğe önem } \\
\text { verdiği, ancak bu içeriklere erişim hakkında } \\
\text { gerekli hassasiyeti göstermedikleri anlaşılabilir. } \\
\text { Site kullanımının kolaylığını ifade eden kulla- } \\
\text { nılabilirlik özelliği \%66, arama motoru uyum- } \\
\text { luluğu ise \%50 oranında olumlu bulunmustur. }\end{array}$} \\
\hline
\end{tabular}


Çalışmanın amaçlarından bir tanesi de incelenen web sitesinin kurum türü ve yaşına göre işlevselliklerinin değişip değişmediğini saptamaktır. Bu bağlamda elde edilen veriler kurum türü temel alınarak t-test analizleri ile, yaş aralığı temel alınarak da ANOVA analizleri ile incelenerek Tablo 5 ve 6'da gösterilmiştir.

Tablo 5. Kurum Türüne Göre İşlevsellik Puanları Karşılaştırması

\begin{tabular}{|c|c|c|c|c|c|c|c|}
\hline & Grup & $N$ & $X$ & $S S$ & $t$ & $d f$ & $p$ \\
\hline \multirow[t]{2}{*}{ İçerik } & Devlet & 79 & 32,8 & 3,96 & 1,116 & 92 & 0,267 \\
\hline & Vakıf & 15 & 31,5 & 5,78 & & & \\
\hline \multirow[t]{2}{*}{ Kullanılabilirlik } & Devlet & 79 & 9,8 & 2,17 & $-0,213$ & 92 & 0,832 \\
\hline & Vakıf & 15 & 10,0 & 2,26 & & & \\
\hline \multirow[t]{2}{*}{ Erişilebilirlik } & Devlet & 79 & 7,6 & 1,95 & $-1,040$ & 92 & 0,301 \\
\hline & Vakıf & 15 & 8,1 & 1,64 & & & \\
\hline \multirow[t]{2}{*}{ Arama Motoru Uyumluluğu } & Devlet & 79 & 11,6 & 2,99 & 0,836 & 92 & 0,406 \\
\hline & Vakıf & 15 & 10,8 & 3,68 & & & \\
\hline \multirow[t]{2}{*}{ Toplam } & Devlet & 79 & 61,8 & 7,33 & 0,640 & 92 & 0,524 \\
\hline & Vakıf & 15 & 60,4 & 9,53 & & & \\
\hline \multirow{5}{*}{\multicolumn{2}{|c|}{$\begin{array}{l}\text { Tablo 5’te incelenen web sayfalarının elde ettiği } \\
\text { puanların, devlet ve vakıf üniversiteleri arasın- } \\
\text { da karşılaştırılması için yapılan t-test analizle- } \\
\text { rinin sonucunu göstermektedir. Görüleceği gibi } \\
\text { incelenen web sitelerinin işlevsellikleri, devlet }\end{array}$}} & \multirow{6}{*}{\multicolumn{6}{|c|}{$\begin{array}{l}\text { hem ana başlıklarda hem de toplam puanda } \\
\text { herhangi bir anlamlı farklılık göstermemekte- } \\
\text { dir. Bu da devlet ve vakıf üniversitelerinin } \\
\text { kurum web sitelerini benzer işlevselliklere } \\
\text { sahip bir şekilde tasarladıklarını ve kullandık- } \\
\text { larını göstermektedir. }\end{array}$}} \\
\hline & & & & & & & \\
\hline & & & & & & & \\
\hline & & & & & & & \\
\hline & & & & & & & \\
\hline \multicolumn{2}{|c|}{ ve vakıf kurumları (üniversiteleri) arasında } & & & & & & \\
\hline
\end{tabular}

Tablo 6. Kurum Yaşlarına Göre İşlevsellik Puanları Karşılaştırması

\begin{tabular}{|c|c|c|c|c|c|}
\hline & Kareler Toplamı & SS & $\begin{array}{c}\text { eler Ort } \\
\text { masi }\end{array}$ & $f$ & $p$ \\
\hline \multicolumn{6}{|l|}{ İçerik } \\
\hline Gruplar Arası & 268,961 & 3 & 89,654 & 5,578 & $0,001^{*}$ \\
\hline Grup İçi & 1446,627 & 90 & 16,074 & & \\
\hline Toplam & 1715,588 & 93 & & & \\
\hline \multicolumn{6}{|l|}{ Kullanılabilirlik } \\
\hline Gruplar Arası & 7,711 & 3 & 2,570 & 0,535 & 0,659 \\
\hline Grup İçi & 432,100 & 90 & 4,801 & & \\
\hline Toplam & 439,811 & 93 & & & \\
\hline \multicolumn{6}{|l|}{ Erişebilirlik } \\
\hline Gruplar Arası & 4,273 & 3 & 1,424 & 0,385 & 0,764 \\
\hline Grup İçi & 332,921 & 90 & 3,699 & & \\
\hline Toplam & 337,194 & 93 & & & \\
\hline \multicolumn{6}{|c|}{ Arama Motoru Uyumluluğu } \\
\hline Gruplar Arası & 11,256 & 3 & 3,752 & 0,384 & 0,765 \\
\hline
\end{tabular}




\begin{tabular}{lccccc} 
Grup İçi & 880,478 & 90 & 9,783 & & \\
Toplam & 891,734 & 93 & & & \\
\hline Toplam & & & & & \\
$\quad$ & 302,963 & 3 & 100,988 & 1,754 & 0,162 \\
$\quad$ Gruplar Arası & 5182,327 & 90 & 57,581 & & \\
Grup İçi & 5485,290 & 93 & & & \\
$\quad$ Toplam & & & &
\end{tabular}

Kurumların yaş aralığı incelenerek yapılan ANOVA testi sonucuna göre (Tablo 6), eğitim fakültesi web sitesi işlevselliği sadece içerik yönünden farklılık göstermiştir, $F(3,90)=5.578$, $\mathrm{p}<.05$. Ortaya çıkan anlamlı farkın hangi yaş aralıkları arasında olduğunu tespit etmek için yapilan post-hoc (Tukey) testinin sonucuna göre; kuruluş yaşı 1-10 arasında olan eğitim fakültelerinin web sayfaları, yaşı 11-20 ve 21-30 olan eğitim fakültelerinin web sayfalarına göre içerik yönünden anlamlı olarak daha düşük işlevselliğe sahiptir.

\section{TARTIŞMA ve SONUÇ}

Eğitim fakültelerinin web siteleri incelendiğinde genel olarak sitelerde içerik (76\%) ve kullanulabilirlik (66\%) kriterlerine arama motoru uyumluluğu (50\%) ve erişilebilirlik (41\%) kriterlerine oranla daha fazla önem verildiği görülmektedir. Yukarıda bahsi geçen kriterler açısından devlet ve vakıf üniversiteleri arasında benzerlik bulunmaktadır.

Eğitim fakültelerinin sitelerinde içeriğe ve kullanılabilirliğe önem verilmesinin temel sebebi olarak internetin özellikle 1990'lı yıllarda varlığını göstermesiyle Web 1.0'ı içeren web sitelerinin oluşturulması gösterilebilir. $\mathrm{Bu}$ yapıda site ziyaretçisi sadece bilgiye ulaşan ve bilgi edinen rolündedir. Bu anlayışın benimsenmesi içerik ve kullanılabilirliğin önemini ortaya koymaktadır. Bu bağlamda kurumlar Web 1.0 kapsamındaki anlayışa göre web sitelerini düzenlemişlerdir. Ancak, 2000'li y1llardan sonra Web 2.0 ve Web 3.0 teknolojileri yaygınlaşsa da aslında üniversiteler bu gelişi- me beklendiği şekilde ayak uyduramamıştır. Erişilebilirlik ve arama motoru uyumluluğu maddeleri incelendiğinde bu teknolojileri kapsadığını görülmektedir. Erişilebilirlik ve arama motoru uyumluluğu bulgularının daha düşük olması üniversitelerin web sitelerinde Web 2.0 ve Web 3.0 teknolojilerine yer vermesi gerektiğini işaret etmektedir. Diğer bir ifade ile eğitim fakültelerinin web siteleri son yıllarda yaşanan web teknolojisi alanındaki gelişmeleri web sitelerine tam olarak yansıtamamıştır.

Araştırmada kullanılan değerlendirme formu bulgularında içerik puan ortalamalarının yeni kurulan üniversitelerde eski üniversitelere göre istatistiksel olarak anlamlı bir fark oluşturduğu ve bu farkın önceden kurulan üniversitelerin lehine bir durum olduğu tespit edilmiştir. Çalışmada elde edilen bulgular incelendiğinde Türkiye'deki üniversitelerin \%68'inin 2000'li yıllardan sonra kurulmuş olduğu görülmektedir. Bu üniversitelerin çoğu aslında ilk defa kurulan bir üniversite nitelendiğinden ziyade, daha önce kurulmuş olan üniversitelerden ayrılan kurumlardır. Bu bağlamda yeni kurulan üniversitelerin web sitesi işlevselliği alanda çalışmalarını geliştirmesi gerekmektedir.

Çalışmada elde edilen sonuçlara göre genel olarak eğitim fakültesi web sitelerinin geliştirilmesinde öncelikle erişilebilirlik ve arama motoru uygunluğu açısından öncelik vermeleri gerekmektedir. Yeni kurulan üniversitelerin ise öncelikli olarak içeriğe ardından diğer alanlara ağırlık vermeleri ve sitelerini geliştirmeleri önerilmektedir. 


\section{Kaynakça}

Astani, M., ve Elhindi, M. (2008). An empirical study of university websites.Issues in Information Systems, $9(2), 460-465$.

Ateş, V. ve Karacan, H. (2009) Abant İzzet Baysal Üniversitesi Web Sitesi Kullanılabilirlik Analizi, International Journal of Informatics Technologies , 2 (2), 33-38.

Atterer, R., Wnuk, M. ve Schmidt, A. (2006, May). Knowing the user's every move: user activity tracking for website usability evaluation and implicit interaction. In Proceedings of the 15th international conference on World Wide Web (203-212). ACM.

Brophy, P. and Craven, J., (2007). Web Accessibility. Library Trends. 55(4), 950-972.

Chiew, T. K., ve Salim, S. S. (2003). Webuse: Website usability evaluation tool. Malaysian Journal of Computer Science, 16(1), 47-57.

Çoban S., Tüfekçi S. (2015) Kurumsal İletişim Bağlamında Türkiye'deki Devlet Üniversitelerinin Web Sayfaları Üzerine Bir İnceleme, International Periodical For The Languages, Literature and History of Turkish or Turkic Volume 10/6, 387-402

Dal, N. E. ve Dal, V. (2015). Kişilik Özellikleri Ve Sosyal A ̆ Sitesi Kullanım Alışkanlıkları: Üniversite Öğrencileri Üzerine Bir Araştırma-Personality Traits And Social Network Sites Usage Habits: A Research On University Students. Mehmet Akif Ersoy Üniversitesi Sosyal Bilimler Enstitüsü Dergisi, 6(11), 144-162.

Elges, M (2002, July 1). Web site redesign knowing when it's time. The Secured Lender, 74-76.

Elges, M (2004, November 15). Why worry about web site usability?. Credit Union Executive Newsletter, p. 8 .

Flavián, C., Guinalíu, M., ve Gurrea, R. (2006). The role played by perceived usability, satisfaction and consumer trust on website loyalty. Information $\mathcal{E}$ Management, 43(1), 1-14.

Gullikson, Shelley, ve diğerleri. (1999). The impact of information architecture on academic Web site usability. The Electronic Library. 17 (5), 293-304.

Hackett, S., Parmanto, B. ve Zeng, X. (2004, October). Accessibility of Internet websites through time. In ACM SIGACCESS Accessibility and Computing, 77-78, 32-39. ACM.

Hillier, M. (2003). The role of cultural context in multilingual website usability. Electronic Commerce Research and Applications, 2(1), 2-14.

Khazaal, Y., Chatton, A., Zullino, D., ve Khan, R. (2012). HON label and DISCERN as content quality indicators of health-related websites. Psychiatric Quarterly, 83(1), 15-27.

Kyleschaeffer (2015). Screenfly / Test Your Website at Different Screen Resolutions, Homepage, $<$ http://quirktools.com/screenfly> (05.Haziran 2015).

Lawrence, S., ve Giles, C. L. (1999). Accessibility of information on the web. Nature, 400, 107-107. 
Lazar, J., Beere, P., Greenidge, K., ve Nagappa, Y. (2003). Web accessibility in the mid-Atlantic United States: a study of 50 web sites. Universal Access in the Information Society, 2(4), 1-11

Lazar, J., Dudley-Sponaugle, A., ve Greenidge, K. D. (2004). Improving web accessibility: a study of webmaster perceptions. Computers in Human Behavior, 20(2), 269-288.

Liu, G. Z., Liu, Z. H., ve Hwang, G. J. (2011). Developing multi-dimensional evaluation criteria for English learning websites with university students and professors. Computers $\mathcal{E}$ Education, 56(1), 6579.

Mankoff, J., Fait, H., ve Tran, T. (2005, April). Is your web page accessible?: a comparative study of methods for assessing web page accessibility for the blind. In Proceedings of the SIGCHI conference on Human factors in computing systems (41-50). ACM.

Morkes, J., ve Nielsen, J., (1997). Concise, scannable and objective: How to write for the Web, Retrived from: http://useit.com/papers/webwriting/writing.html.

Nielsen, J (2000). Designing Web Usability. Indianapolis, Indiana: New Riders.

Nielsen, J. (1999). User interface directions for the web. Communications of the ACM, 42(1), 65-72.

Norman, D. A. (1988). The psychology of everyday things. Doubleday, New York: Basic Books.

Richards, J. T., ve Hanson, V. L. (2004, May). Web accessibility: a broader view. In Proceedings of the 13th international conference on World Wide Web (72-79). ACM.

Sohn, T., Li, K. A., Griswold, W. G., ve Hollan, J. D. (2008, April). A diary study of mobile information needs. In Proceedings of the SIGCHI Conference on Human Factors in Computing Systems (pp. 433442). ACM.

Spindler, T. (2002). The accessibility of web pages for mid-sized college and university libraries. Reference $\mathcal{E}$ User Services Quarterly, 42(2), 149-154.

Stover, M., ve Zink, S. D. (1996). World Wide Web home page design: patterns and anomalies of higher education library home pages. Reference Services Review, 24(3), 7-20.

Sullivan, T., ve Matson, R. (2000, November). Barriers to use: usability and content accessibility on the Web's most popular sites. In Proceedings on the 2000 conference on Universal Usability (pp. 139-144). ACM.

Thompson, T., Burgstahler, S., ve Comden, D. (2003). Research on web accessibility in higher education.Journal of Information Technology and Disabilities, 9(2).

Zhang, J., ve Dimitroff, A. (2005). The impact of webpage content characteristics on webpage visibility in search engine results (Part I). Information Processing \& Management, 41(3), 665-690 


\section{Extended Summary}

Internet has an important role in our lives to access desired information. Due to technological improvements, it has been easier to use Internet connections for various purposes including shopping, communication, and entertainment. It is obvious that websites are the most popular environments that users visit to benefit from online contents. This trend has increased the importance of websites' functionality because there are numerous websites that are waiting for visitors. The quality of websites is very important because they need to impress visitors with their features. In other words, they need to follow general website standards. In addition, websites need to be reviewed and updated regularly with the needs of potential users (Elges, 2002). According to Elges (2004), when a website is designed, there are five important factors that need to be taken into consideration including 1-Users, 2- Purpose and goals, 3Tasks,4-Environmental Challenges, 5-Technology. Users are important because they are customers of websites. Hence, they need to be satisfied. In addition, purpose and goals of web sites, and tasks of every single webpage should be prepared and organized very carefully. Lastly, a designed website needs to be accessed via users' current technology without any environmental challenges regarding to users' personal needs.

In order to build a full functioned website there are four general aspects to be considered carefully.

Content: Content is one of the most important elements in a website because users mostly visit them for their content (Nielsen, 1999; Richards \& Hanson, 2004). Therefore, there should not be useless and aged information in a website. Moreover, the content needs to be supported with multiple visuals such as images, graphs, and animations.

Usability: Different users may have various needs and characteristics. Hence, websites need to satisfy diverse user groups. In other words, the design needs to be user friendly that facilitate the navigation in the website. That is, users should be able to access the website content easily even they are fist time visitors.

Accessibility: A website could be very usable and have very rich content. However, if it is not accessible, it would be useless. Accessibility can be defined as accessing the content without any barriers or environmental challenges (Mankoff, Fait, \& Tran, 2005). That is, websites need to be designed and served users' technical devices in mind. In other words, a website needs to be supported by majority of users' computers or related technologies to be accessed desired content. In addition, some users may have some special needs. For example, older users may have visual disorder. Thus, the web site should have some features to facilitate seeing.

Search Engine Optimization: Search engine optimization is the process to increase the traffic of a web site receives from search engines. As stated above, users want to access to web sites to find what they are looking for. Search engines try to help these users to find appropriate web sites. There are some techniques to make a web site more visible and reachable through search engines. Web designers need to take these techniques into consideration to ensure that users will be able to find their websites when they need.

The main purpose of this study was to investigate the functionality of Faculty of Education websites in Turkey based on content, usability, accessibility, and search engine optimization. A total of ninety-four websites were scored with the Web Site Functionality Evaluation form. 
Descriptive statistics, t-test, and ANOVA analyses were used to interpret the obtained data. In general web sites were satisfactory based on content. However, they had drawbacks regarding to accessibility.

In terms of institution types, there were no significant differences among public and non-public universities based on content, usability, accessibility, and search engine optimization scores. When the ages of institutions were considered, the websites' content of the new institutions is significantly less competence than the institutions that are more than 10 years old.

In general, Faculty of Education websites are not accomplished in new universities. This finding shows us that these institutions do not care their websites as needed. In order to make their websites better, Education Faculties need to have new approaches to improve their web sites based on suggestions in the literature. Especially, accessibility and search engine optimization need to be taken into consideration in website upgrades because content and usability seem acceptable. 